\title{
Correction: Wearable Digital Sensors to Identify Risks of Postpartum Depression and Personalize Psychological Treatment for Adolescent Mothers: Protocol for a Mixed Methods Exploratory Study in Rural Nepal
}

Anubhuti Poudyal $^{1 *}$, MPH; Alastair van Heerden ${ }^{2,3}$, PhD; Ashley Hagaman ${ }^{4,5}, \mathrm{MPH}, \mathrm{PhD}$; Sujen Man Maharjan ${ }^{6}$, MA; Prabin Byanjankar ${ }^{6}$, MSc; Prasansa Subba ${ }^{7}$, MPhil; Brandon A Kohrt ${ }^{1 *}, \mathrm{MD}, \mathrm{PhD}$

${ }^{1}$ Division of Global Mental Health, Department of Psychiatry and Behavioral Sciences, George Washington School of Medicine and Health Sciences, Washington, DC, United States

${ }^{2}$ Human and Social Development, Human Sciences Research Council, Pietermaritzburg, South Africa

${ }^{3}$ Medical Research Council/Wits Developmental Pathways for Health Research Unit, Department of Paediatrics, Faculty of Health Sciences, University of the Witwatersrand, Johannesburg, South Africa

${ }^{4}$ Department of Social and Behavioral Sciences, Yale School of Public Health, Yale University, New Haven, CT, United States

${ }^{5}$ Center for Methods in Implementation and Prevention Science, Yale University, New Haven, CT, United States

${ }^{6}$ Transcultural Psychosocial Organization Nepal, Kathmandu, Nepal

${ }^{7}$ United Mission to Nepal, Kathmandu, Nepal

*these authors contributed equally

\section{Corresponding Author:}

Brandon A Kohrt, MD, PhD

Division of Global Mental Health

Department of Psychiatry and Behavioral Sciences

George Washington School of Medicine and Health Sciences

2120 L Street, Suite 600

Washington, DC, 20037

United States

Phone: 1 (202) 7412888

Email: bkohrt@gwu.edu

\section{Related Article:}

Correction of: https://www.researchprotocols.org/2019/9/e14734/

(JMIR Res Protoc 2019;8(10):e16837) doi: 10.2196/16837

In "Wearable Digital Sensors to Identify Risks of Postpartum Depression and Personalize Psychological Treatment for Adolescent Mothers: Protocol for a Mixed Methods Exploratory Study in Rural Nepal" by Poudyal et al (JMIR Res Protoc 2019;8(9):e14734), a minor error in the typesetting stage of publication resulted in the International Registered Report Identifier (IRRID) not being included in the final version of the article.
The IRRID "DERR1-10.2196/14734” has now been added to the paper.

The correction will appear in the online version of the paper on the JMIR website on October 30, 2019, together with the publication of this correction notice. Because this was made after submission to PubMed, PubMed Central, and other full-text repositories, the corrected article has also been resubmitted to those repositories. 
This is a non-peer-reviewed article. Submitted 29.10.19; accepted 29.10.19; published 30.10.19.

Please cite as:

Poudyal A, van Heerden A, Hagaman A, Maharjan SM, Byanjankar P, Subba P, Kohrt BA

Correction: Wearable Digital Sensors to Identify Risks of Postpartum Depression and Personalize Psychological Treatment for

Adolescent Mothers: Protocol for a Mixed Methods Exploratory Study in Rural Nepal

JMIR Res Protoc 2019;8(10):e16837

URL: http://www.researchprotocols.org/2019/10/e16837/

doi: $10.2196 / 16837$

PMID: $\underline{31671057}$

(C)Anubhuti Poudyal, Alastair van Heerden, Ashley Hagaman, Sujen Man Maharjan, Prabin Byanjankar, Prasansa Subba, Brandon A Kohrt. Originally published in JMIR Research Protocols (http://www.researchprotocols.org), 30.10.2019. This is an open-access article distributed under the terms of the Creative Commons Attribution License (https://creativecommons.org/licenses/by/4.0/), which permits unrestricted use, distribution, and reproduction in any medium, provided the original work, first published in JMIR Research Protocols, is properly cited. The complete bibliographic information, a link to the original publication on http://www.researchprotocols.org, as well as this copyright and license information must be included. 